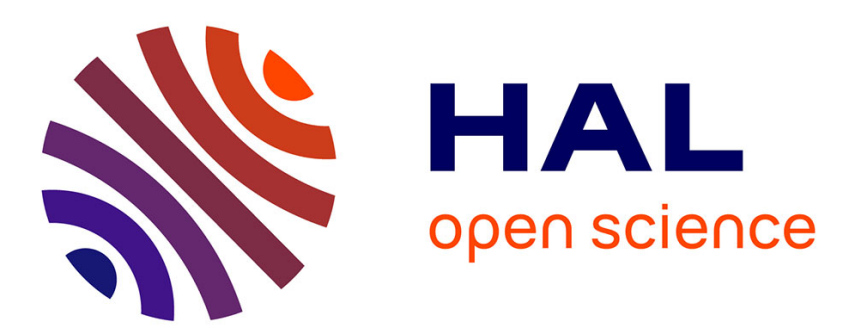

\title{
Permeability of gases In the anode of An anode-supported SOFC
}

Maya Geagea, Ivaylo Genov, Zdravko Stoynov, Daria Vladikova, Anthony Chesnaud, Alain Thorel

\section{- To cite this version:}

Maya Geagea, Ivaylo Genov, Zdravko Stoynov, Daria Vladikova, Anthony Chesnaud, et al.. Permeability of gases In the anode of An anode-supported SOFC. SOFC-XIV: Anodes 2, Jul 2015, Glasgow, United Kingdom. 10.1149/06801.1185ecst . hal-01195562

HAL Id: hal-01195562

https://hal-mines-paristech.archives-ouvertes.fr/hal-01195562

Submitted on 8 Sep 2015

HAL is a multi-disciplinary open access archive for the deposit and dissemination of scientific research documents, whether they are published or not. The documents may come from teaching and research institutions in France or abroad, or from public or private research centers.
L'archive ouverte pluridisciplinaire HAL, est destinée au dépôt et à la diffusion de documents scientifiques de niveau recherche, publiés ou non, émanant des établissements d'enseignement et de recherche français ou étrangers, des laboratoires publics ou privés. 


\title{
Permeability of Gases In the Anode of An Anode-Suported SOFC
}

\author{
Maya Geagea ${ }^{\mathrm{a}}$, Ivaylo Genov ${ }^{\mathrm{b}}$, Zdravko Stoynov $^{\mathrm{b}}$, \\ Daria Vladikova $^{\mathrm{b}}$, Anthony Chesnaud ${ }^{\mathrm{a}}$, Alain Thorel ${ }^{\mathrm{a}}$ \\ ${ }^{a}$ Centre des Matériaux, Mines-ParisTech, PSL, UMR CNRS 7633, BP 87, 91003 \\ Evry Cedex, France \\ ${ }^{b}$ Institute of Electrochemistry and Energy Systems - Bulgarian Academy of Sciences, \\ 10 Acad. G. Bonchev St., Sofia 1113, Bulgaria
}

\begin{abstract}
In the high current density regime, the performance of SOFCs is limited by concentration overpotentials when the demand for reactants exceeds the capacity of the porous cermet anode to supply them by gas diffusion mechanisms, and when the rate at which water is produced exceeds the ability of the anode to evacuate water. A compromise should be found between maintaining a high level of activation in the anode, which means a high density of Triple Phase Boundaries (TPB) usually associated with small grains size and small pores, and high gas permeability generally associated with large interconnected pores. The present work aims at determining experimentally the gas permeability of the anode as a function of the percolation, tortuosity and volume fraction of the pores. Anodes with varying porosity ensured by different quantities of pore former were obtained by cold pressing and sintering. SEM image analysis, mercury intrusion porosimetry and permeability measurements for different gases were performed. However, non-linearity as a function of the gases molecular weight is observed.
\end{abstract}

\section{Introduction}

In electrolyte-supported solid oxide fuel cell, the ohmic contribution to over-potential is large because of high resistivity of the electrolyte. These cells operate at high temperature $\left(1000^{\circ} \mathrm{C}\right)$ where the mobility of mobile ions is enhanced. But high operating temperature induces high costs, requires specific sealing and sophisticated interconnects and may result in poor cell durability because of active diffusion of species. Therefore, anode-supported fuel cells with thin associated electrolyte layer were extensively investigated for intermediate temperature operation $\left(600-800^{\circ} \mathrm{C}\right)$ in the last few years in order to improve the electrochemical performance and the cell durability for long-term operation. The performance of a SOFC is controlled by various polarizations or losses: ohmic losses (due to the electrical resistance of the components), activation losses (due to low kinetics of charge transfer of the electrochemical reactions; it mainly depends on the electrode-electrolyte interface) and concentration losses (when the transport of fuel and the transport of products of reaction are retarded). Even though thin electrolyte layer in anode-supported cell reduces drastically the electrolyte ohmic contribution, activation and concentration polarizations of the anode still penalize the cell performances. 
Therefore, an optimization of the overall performance of the fuel cell requires optimizing the parameters which control the activation and concentration overpotentials. In this aim, several studies show the strong impact of microstructure parameters (1) on the electrode performance. According to Virkar et al. (2), Sakamoto et al (3) and Lee et al. (5), the microstructural characteristics of the anode in anodesupported SOFCs are considered having crucial effects on the electrochemical performance, and more specifically on the concentration polarization. This latter occurs when the demand for reactants exceeds the capacity of the porous cermet anode to supply them by gas diffusion mechanisms (4) and, in the case of a SOFC anode, when the rate at which water is produced exceeds the ability of the porosity to evacuate water. It is obviously related to the anode microstructure in terms of porosity (tortuosity, pore volume fraction, size and distribution). In consequence, an appropriate path for the gases reduces the diffusional (concentration) polarization loss. Since the various requirements for an efficient anode (high ionic and electronic conductivity, homogeneous distribution of all phases and uniform percolation, high gas permeability for transport of hydrogen and of reaction products, fine particle size for high electro-catalytic activity) could not be all investigated in one anode layer in order to achieve high power densities (6-9), the investigation of our case study is only limited to the modification of the porosity characteristics by using graphite pore former particles and conventional materials (YSZ and Ni).

Three potential diffusional mechanisms can occur once the gas is passing through porous electrodes. These mechanisms depend essentially on the nature of the gas and on the microstructure of the porous medium (anode). The three mechanisms are: Molecular, Viscous and Knudsen diffusion. According to W.He et al (10), in the case of porous media having the pore diameter much larger than the mean free path of gas molecules at a given temperature, the binary diffusion (also called the Darcy regime) takes the advantage over the Knudsen diffusion process. The effective diffusion coefficient is then defined based on Fick's Law as an approach to evaluate gas diffusion as Equation [1]:

$$
D_{i j}^{i f f}=\frac{\emptyset}{\tau} D_{i j}
$$

where $\mathrm{D}_{\mathrm{ij}}$ is the binary diffusivity, $\varnothing$ the porosity (vol\%) and $\tau$ the tortuosity of the porous electrode. However, if the diffusion is taking place in porous media having small pores, with low pressure, Knudsen diffusion will take place since the interactions involve more frequent collisions between gas molecules and walls of the porous media than with other gas molecules. Cases exist where both mechanisms Knudsen and molecular one are very important. Then the total diffusivity of gas species is written as shown in Equation [2]:

$$
\frac{1}{D_{i}^{t}} \cong \frac{1}{D_{i j}}+\frac{1}{D_{i K}}
$$

where $D_{i j}$ is the ordinary binary diffusion coefficient of two species ( $i$ in $j$ ) defined as following from the Chapman-Enskog theory Equation [3]:

$$
D_{i j}=\frac{0,00186 T \frac{1}{2}}{p \sigma_{i j}^{2} \Omega}\left(\frac{1}{M_{i}}+\frac{1}{M_{j}}\right)^{\frac{1}{2}}
$$

$\mathrm{M}_{\mathrm{i}}$ and $\mathrm{M}_{\mathrm{j}}$ are molecular weight $\left(\mathrm{g} \cdot \mathrm{mol}^{-1}\right), \mathrm{p}$ is the total pressure (atm), $\mathrm{R}$ is the ideal 
gas constant $\left(\mathrm{J} \mathrm{Kg}^{-1} \mathrm{~K}^{-1}\right)$, T is the temperature in $\mathrm{K}, \sigma_{\mathrm{ij}}$ and dimensionless $\omega_{\mathrm{D}}$ are Lennard-Jones parameters. $\mathrm{D}_{\mathrm{iK}}$ is the Knudsen diffusivity with $\mathrm{d}_{\mathrm{p}}$ as the mean pore size as given in Equation [4]:

$$
D_{i K}=\frac{d_{p}}{3} \sqrt{\frac{8 R T}{\pi M_{i}}}
$$

Taking in consideration that in most porous media, especially in compact solid, paths for the diffusion of gas molecules within the pores are random and tortuous, the effective diffusion coefficient is therefore given by Eq [5]:

$$
D_{i}^{t_{i} \text { eff }}=\frac{\emptyset}{\tau} D_{i}^{t}
$$

In this study, our effort to develop anode substrate for the practical application of the low or intermediate temperature anode-supported type SOFC is reported. Our studies focused on the optimization of the anode microstructure through permeability and mercury porosimetry tests for anode substrates prepared using cold pressing.

\section{Experimental procedures}

Yttria-stabilized zirconia (Tosoh, Japan) and nickel oxide (Novamet, USA) were used to prepare NiO-YSZ composite anodes. The average particle size of YSZ and NiO was 0.1 and $4 \mu \mathrm{m}$ respectively. The pre-mixed powders were ball-milled for 3 hours. We added plate shaped graphite $(0,15,20$ and 25 vol \% respectively) with $2 \mu \mathrm{m}$ in diameter to provide the additional porosity of anode substrate to the appropriate level. The granules of NiO-YSZ mixture were compacted and uniaxially pressed into pellets with $1.5 \mathrm{~mm}$ in thickness and $25 \mathrm{~mm}$ in diameter, and then sintered at $1350{ }^{\circ} \mathrm{C}$ in air. The porosity of the NiO-YSZ composite was measured via $\mathrm{Hg}$ porosimetry. The microstructure of the various NiO-YSZ composite samples was investigated with a scanning electron microscope (SEM FEG FEI Nova NanoSEM 450) combined with Image Analysis. For this purpose, the investigated samples were impregnated in resin and polished. The numerical images were segmented to isolate pores and allow calculating the pore volume percentage using MATLAB software package. An average of 15 micrographs were taken for each sample to ensure the robustness of the analysis (homogeneous distribution of pores throughout the whole sample, at the edges as well as in the core). The maximum error for the analysis lies within 5\%.

Four different volume percentages of pore formers were investigated; for each percentage, two samples were studied before and after reduction. Table I summarizes the different samples under consideration. Samples with the annotation (G) represent unreduced samples and (B) is for reduced samples in $\mathrm{H}_{2}$. Reduction of samples was carried out in situ at $700^{\circ} \mathrm{C}$ in a $10 \% \mathrm{H}_{2}+90 \% \mathrm{~N}_{2}$ mixture for 2 hours prior to measurements. The fuel flow rate was maintained at $140 \mathrm{~mL} / \mathrm{min}$. 
TABLE I. Volume fraction of pores in different samples

\begin{tabular}{|c|c|c|c|c|c|c|c|c|}
\hline Samples & A1(G) & A1(B) & A2(G) & A2(B) & A4(G) & A4(B) & A6(G) & A6(B) \\
\hline $\begin{array}{c}\text { Graphite } \\
\text { (vol\%) }\end{array}$ & 0 & 0 & 15 & 15 & 20 & 20 & 25 & 25 \\
\hline
\end{tabular}

\section{Results and discussion}

\section{III.1 Microstructural analysis}

In an attempt to promote a high porosity, and to favour a percolating distribution of $\mathrm{Ni}$ within the anode, a hierarchical microstructure was looked for in the final material by purposely interrupting the grinding step prior to sintering. Therefore, mixing $\mathrm{NiO}$ particles with YSZ granulates will lead in the final anode to the repartition of a network of pores and $\mathrm{Ni}$ surrounding a skeleton of significantly large YSZ grains. This hierarchical microstructure appears positive in terms of conductivity and limited concentration overpotentials, but must be thoroughly tailored since large final granulates do not play in favour of an increase of TPB. SEM micrographs of the four samples A1, A2, A4, and A6 are given in Figure 1(a)-(b). As expected, all samples present significant granulates. Interestingly, for the same grinding time granulates are increasingly eroded as a function of increasing amount of pore formers (graphite). As anticipated pores and $\mathrm{NiO}$ cover the YSZ skeleton, which leads to an easier percolation for electronic conductivity and gas transport. It is seen that NiO-YSZ sample with $15 \%$ volume graphite has a structure close to that of A1B sample without graphite, but with smaller granulates.

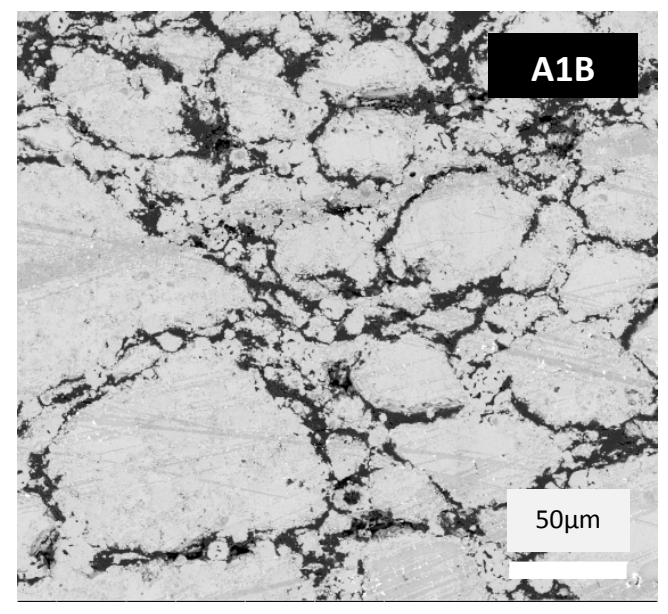

Figure $\quad 1(\mathrm{a})$ : $\quad$ Backscattered

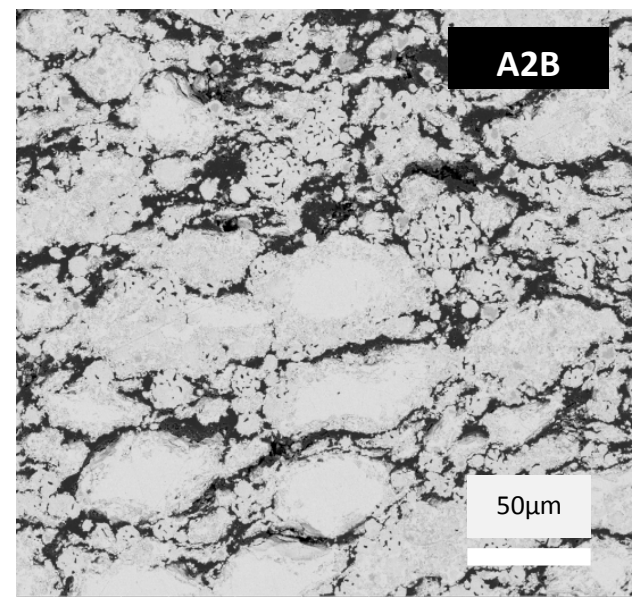

electrons

SEM

micrographs

On the other hand, the compacted pellet with $20 \%$ vol graphite shows similar microstructure to the one with $25 \%$ vol with a serious reduction of granulates size and a drastic increase of porosity. Results of Image Analysis of the microstructure of all the investigated samples (Figure 2) are summarized in Table II. Though a general trend toward an increase of porosity as a function of increasing amount of pore former is found, a significant discrepancy is observed between the measurements of porosity by $\mathrm{Hg}$ porosimetry and by Image Analysis, especially for large volume fractions. Though $\mathrm{Hg}$ porosimetry is known to be less efficient to assess very small pores, small pores do not account for much in the total volume fraction. 

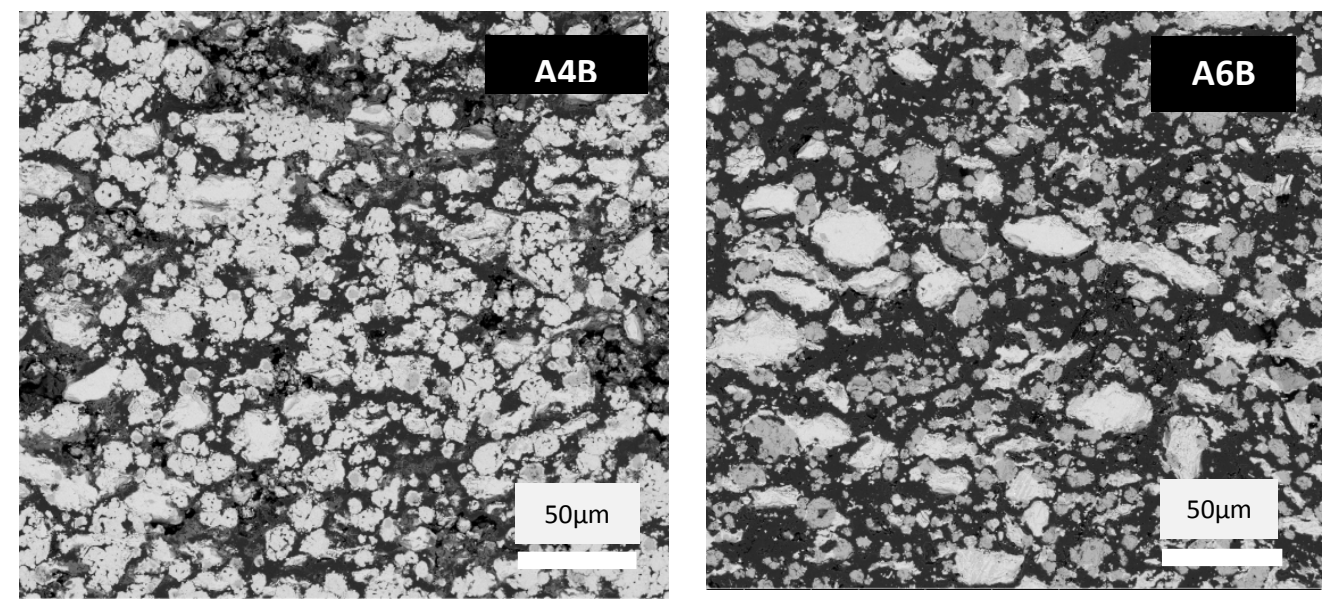

Figure 1(b): Backscattered electrons SEM micrographs of samples sintered with $20 \%, 25 \%$ graphite

Though Image Analysis has been carried out thoroughly on back scattered SEM images on sample impregnated with resin, then polished, it seems more probable that the underestimation of the porosity for large volume fraction of pores is due to a segmentation artifact at interfaces between solid phases and resin. On the other hand, about the same value is recorded by $\mathrm{Hg}$ intrusion porosimetry for samples A2 and A4, though A4 has 5\% more of pore former. And finally it is found that the porosity of sample A4 after reduction is smaller than before, which is also counter-intuitive and requires further investigation

\begin{tabular}{|c|c|c|c|c|c|c|c|c|}
\hline $\begin{array}{l}\text { Samples/ } \\
\text { pore } \\
\text { former }\end{array}$ & $\begin{array}{c}\mathrm{A} 1(\mathrm{G}) \\
0 \%\end{array}$ & $\begin{array}{c}\mathrm{A} 1(\mathrm{~B}) \\
0 \%\end{array}$ & $\begin{array}{c}\mathrm{A} 2(\mathrm{G}) \\
15 \%\end{array}$ & $\begin{array}{c}\text { A2(B) } \\
15 \%\end{array}$ & $\begin{array}{c}\mathrm{A} 4(\mathrm{G}) \\
20 \%\end{array}$ & $\begin{array}{c}\text { A4(B) } \\
20 \%\end{array}$ & $\begin{array}{c}\text { A6(G) } \\
25 \%\end{array}$ & $\begin{array}{c}\text { A6(B) } \\
25 \%\end{array}$ \\
\hline Poro Hg & 15 & 24 & 17 & 20 & 15 & 48 & 40 & 55 \\
\hline $\begin{array}{l}\text { Poro } \\
\text { (I.A) }\end{array}$ & - & 24 & - & 23 & 32,5 & 30,6 & 33,1 & 33,1 \\
\hline $\begin{array}{l}\text { Mean } \\
\text { Pore } \varnothing \\
\text { Volume } \\
(\mu \mathrm{m})\end{array}$ & 1,5 & 2,8 & 2,5 & 2,4 & 2,9 & 3,6 & 4 & 4,4 \\
\hline
\end{tabular}

Distribution of grain size

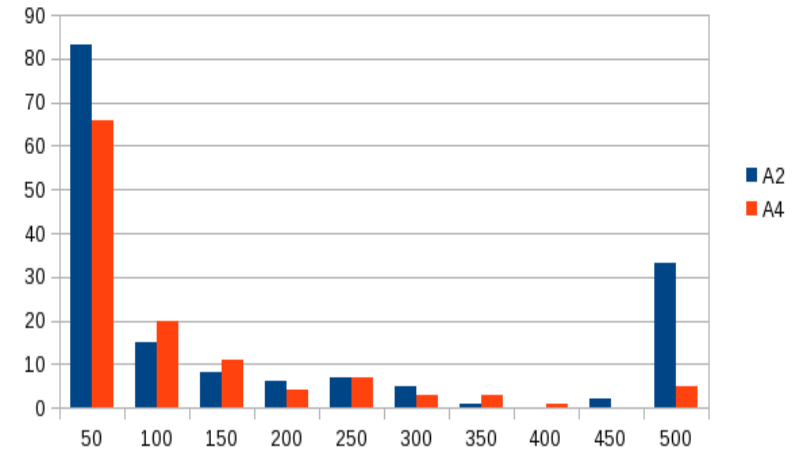

Figure 2. Comparision of distribution of pores after reduction through Image Analysis 


\section{III.2 Conductivity measurements}

Conductivity measurements were evaluated on reduced samples by DC resistivity. Measurements were carried out at room temperature applying advanced four points method. No conductivity was noticed for samples with 0 and $15 \%$ pore former while electronic conductivity was recorded for higher amounts. This clearly indicates that the percolation of $\mathrm{Ni}$ is closely related to the distribution of pore formers.

\section{III.3 Permeability analysis}

Permeability analysis was performed on a new testing system especially designed for this purpose. These studies consisted on measuring the permeability resistance as gas penetrates through porous media. It is defined as the ratio of the pressure $P(\mathrm{~mm}$ $\mathrm{H}_{2} \mathrm{O}$ ) over the gas flow $q_{\text {flow }}[\mathrm{mL} / \mathrm{min}]$ :

$$
R_{p}=\frac{p}{q_{\text {flow }}}
$$

Equation [8] is very similar to the Darcy low; however, it is more convenient and illustrative for gases permeability studies in porous ceramic media. The permeability measurements were carried out at room temperature with different gases: air, $\mathrm{O}_{2}, \mathrm{~N}_{2}$, Ar, dry and humidified $\mathrm{H}_{2}$. The gas flows varied from 0 to $140 \mathrm{~mL} / \mathrm{min}$. The humidity $\left(3 \% \mathrm{H}_{2} \mathrm{O}\right.$ ) was ensured by passing the gas flow through watered vessel at room temperature. Two configurations of the gas flow set-up, (i) lateral, and (ii) transversal, were investigated (Figure 4). Measurements in both configurations showed that the lateral configuration could be neglected in the mixed set-up. Moreover, all the investigations were performed using transversal configuration, which combines both directions of gas flow.
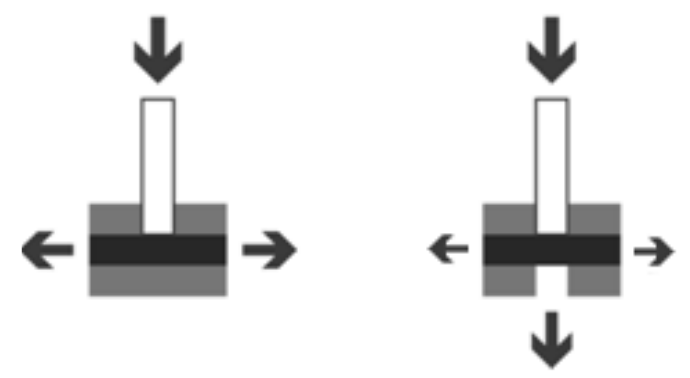

Figure 3.Gas flow configurations of the experimental set-up: (i) lateral; (ii) transversal

As different gases were supplied, the flow of species through the anode layer was provided by the pore structure of the anode. As anticipated and as shown in Figure 5(a), the gas permeability increases with the increase of volume fraction of pore former for non-reduced ones. The correlation with $\mathrm{Hg}$ porosimetry and Image Analysis (IA) on SEM images (see Table II) is especially valid for the highest amounts of pore formers, whereas the difference for lower volume fraction (samples A1G, A2G and A4G) is not significant. Although reduced samples showed higher permeability due to the additional porosity after reduction, (as expected and certified by porosimetry mercury and Image Analysis results listed in Table II), sample A2 showed an increase of the permeability resistance after reduction (See Figure 4(b)). This increase can be explained by a reduction problem. Further investigations on 
samples with the same pore former amount are actually in course to explain more this behavior.

Measurements at room temperature and constant conditions (set-up configuration), for different gases having various molecular weight, registered an increase of the permeability with the decrease of the molecular weight for all the samples before, as well as after reduction (Figure 5(a),5(b)). Argon molecule shows higher permeability even though its molecular weight is the highest among investigated gases. According to James C.Maxwell, since gas molecules have different speeds and different degrees of freedom ( 3 for monoatomic, 5 for diatomic) to each degree of freedom of a molecule is associated a certain kinetic energy. Assuming as a first approximation that the thermal energy will be fully used to ensure translations in the three directions of space (three degrees of freedom), $\mathrm{E}_{\mathrm{kin}}$ is written:

$$
E_{k i m}=\frac{1}{2} m v^{\theta}=\frac{3}{2} k_{B} T
$$

Diatomic gases such as $\mathrm{H}_{2}, \mathrm{O}_{2}, \mathrm{~N}_{2}$ and Air have 5 degrees of freedom, and can therefore store more thermal energy $\left(5 / 2 \cdot \mathrm{k}_{\mathrm{B}} \mathrm{T}\right)$; these molecules have the potential to exhibit a higher translational kinetic energy that could result in a lower permeability than monoatomic gases, as seen in Figure 5 where a kink in permeability is observed for the only monoatomic gas studied in this work. This experimental fact needs further studies and explanation.

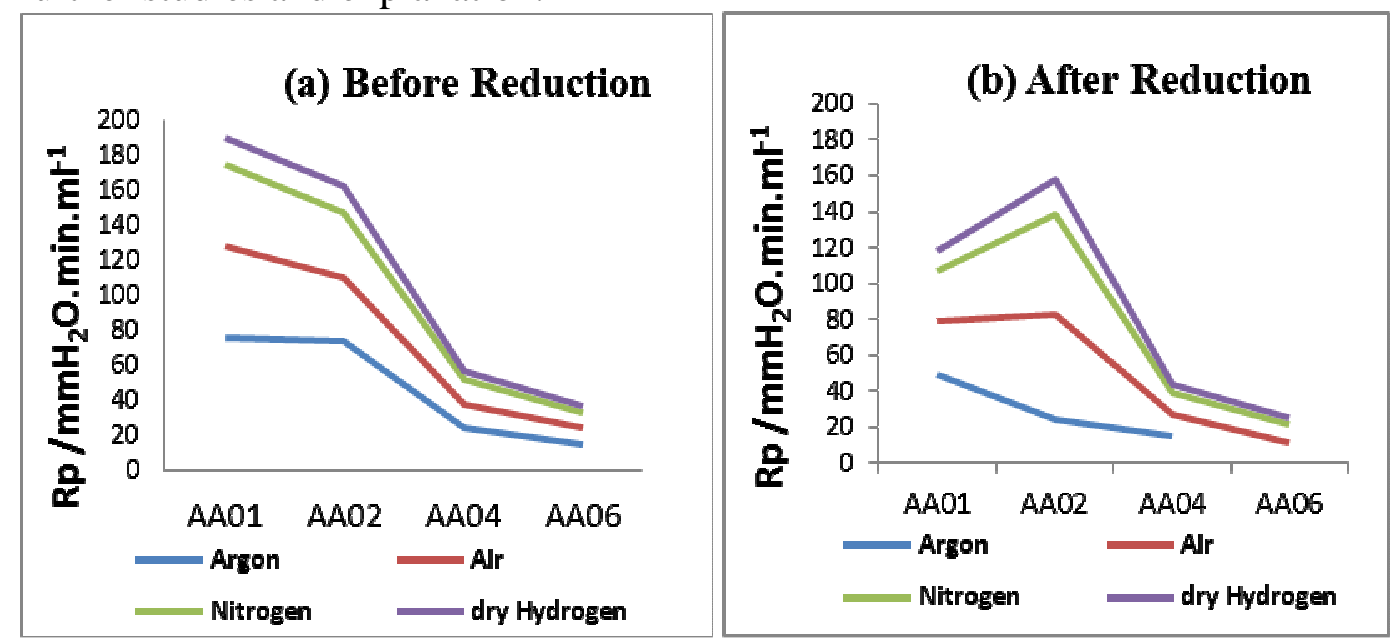

Figure 4: Permeability Resistance as a function of porosity
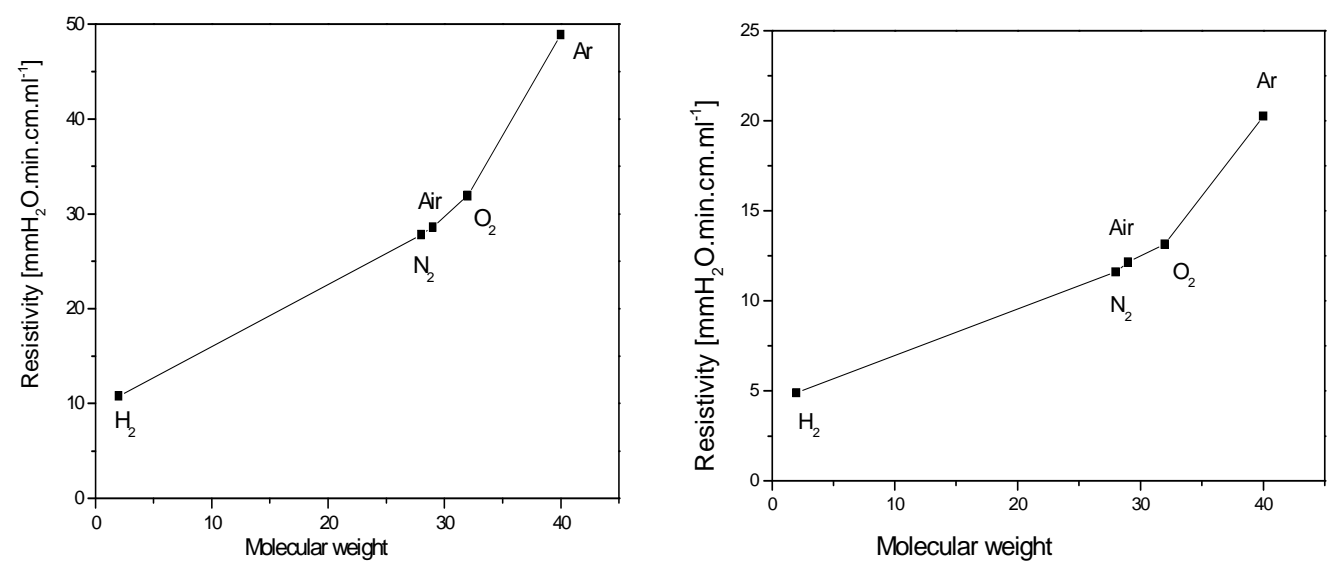

Fig. 5. Dependence between permeability resistivity $\rho_{\mathrm{p}}$ and the gas molecular weight for: (a) sample $\mathrm{NiO} / \mathrm{YSZ}$ before reduction; b) sample Ni/YSZ after reduction 
The observed graphs showed a kink in the vicinity of molecular weights to 28-30 (nitrogen/air). For higher molecular weight (as that of Argon) the resistivity increases faster. This experimental fact needs further studies and explanation.

\section{Conclusion:}

In this study, gas permeation behavior through various pore former volume fractions in anode supports for Intermediate temperature application was investigated. The study was achieved using different gases. Investigations were performed using different analysis techniques such as permeability tests, image analysis and porosimetry mercury intrusion. The results showed that the gas permeability improved by increasing the porosity thus decreasing the size of powder particles. Therefore, the effect of molecular diffusion will become low after a certain volume fraction of pore former and the effect of Knudsen diffusion will be significant. However, gas permeability also depends on molecular weight. The results showed that at a certain pore former volume fraction, the diffusion phenomenon is in a transition region between Knudsen and Molecular diffusion.

\section{References}

1. Q. Cai Claire S. Adjimanb, Nigel P. Brandona Electrochimica Acta 56 (2011) 5804-5814

2. A.V Virkar, J.Chen J, CW Tanner, J-W Kim. Solid State Ionics 131(1e2) (2000) 189-198.

3. Y.Sakamoto, N. Shikazono,N.Kasagi, Journal of Power Sources 193 (2009) 530-540

4. RE Williford, L.A. Chick Surface Science 547 (2003) 421-437

5. J.-H. Leea, *, J.-W. Heoa, D.-S. Leea, J. Kima, G.-H. Kima, H.-W. Leea,

H.S. Songa, J.-H. Moonb Solid State Ionics 158 (2003)

6. G. Matula , T. Jardiel , R. Jimenez, B. Levenfeld, A. Várez, Archive of Materials science and Engineering 32 (1), (2008) 21-25

7. H. Koide Solid State Ionics 132 (2000)

8. S.T. Aruna, M. Muthuraman, K.C. Patil Solid State Ionics 111 (1998) 45-51

9. Nielson F.P. Ribeiro, Mariana M.V.M. Souza, Octavio R. Macedo Neto,

Sonia M.R. Vasconcelos, Martin Schmal, Applied Catalysis A: General 353 (2009) 305-309

10.W.He, W.Lv, J.Dickerson in Journal of Power Sources 237 (2013) 64-73 